\title{
Managing electronic theses and dissertations
}

\author{
The Third International Symposium
}

\author{
by Gail McMillan
}

$\mathrm{N}$ ot many of us would have imagined several years ago that more than 200 people would find dissertations and theses a topic exciting enough to fly, bus, or drive from all over the world to discuss. But the University of South Florida, St. Petersburg campus, hosted the Third International Symposium on Electronic Theses and Dissertations for two-and-ahalf days; we talked, we listened, and we learned.

This was a working meeting and conference themes appealed to the diverse audience, including academic administrators, students, faculty, systems administrators, librarians, publishers, and more.

Many points of view came from outside the library world and outside our national borders. Conference participants came from 13 countries and 34 states plus Washington, D.C. and Puerto Rico, as well as from UNESCO and the Organization of American States. National ETD (electronic theses and dissertation) projects had representatives from Australia, Germany, and Portugal. ETDs are a growing phenomenon on university campuses and there now appears to be a body of knowledgeable people interested in this topic. ${ }^{1}$

Plenary speakers shared their thoughts on preservation (Henry Gladney of IBM), the future (Clifford Lynch of CNI; Richard Bamberger of IBM; and Michael Peirsa of Xerox), metadata (Stuart Weibel of OCLC), and the scholarship (Ann Hart of Claremont Graduate School,
Clifford Lynch, and Jean Claude Guédon of the University of Montreal). Lynch pointed out that the difficult archiving issues are largely organizational, economic, and institutional; the mechanics are relatively easy (Gladney concurred).

Recurring themes from diverse representatives (OCLC and WVU provost) included: don't reinvent the wheel, keep it simple, solicit input widely, formalize relationships. Hart implored us with the popular lyrics "It's not the end of the world, it's just the end of the world as we know it."

Through three plenary panels labeled "Straight Talk," conference participants heard from and interacted with representatives of graduate schools, publishers, and libraries. The first panel consisted of a graduate school dean, a provost, and a vice president of the Council of Graduate Schools. They talked about leadership and enhancing graduate education. One also reminded us that while the dissertation is supposed to be an original and significant contribution, it is also supposed to be an "initial work, not a magnum opus."

\section{EDTs are learning opportunities}

The panel of publishers represented diverse interests but had some common themes also. Delphine Lewis, from UMI, spoke about the tremendous learning opportunities that ETDs present. Eugene Garfield, from Science, implored his colleagues to publish excellent work 
for the benefit of their readership. Janet Fisher, from MIT Press, spoke about the lack of conflict between ETDs and scholarly journal publications due to the major rewrites that chapters require to become journal articles and the importance of the academic journals' peer review processes.

When questioned about the likelihood of plagiarism when research is available through the Internet, all three panelists objected to the notion. Garfield pointed out that plagiarism is also easier to detect and Lewis added that those who are intent on doing it will. Fisher said there is no evidence that plagiarism has increased with the availability of journals online.

The librarians panel included Roy Tennant, California Digital Library Project; Julia Blixrud, ARL; and David Balatti, National Library of Canada. Tennant focused on the problems, reiterating some of Gladney's concerns, especially that libraries are not funded for digital archiving. He noted that ETDs are "a good thing" and that "barriers will fall in time." Blixrud addressed whether to adopt old strategies to new media. Balatti shared background information on the Canadian Theses Service.

\section{Hands-on networking opportunities}

There were many quotable moments, of course. Bruce Cochrane (University of South Florida, Evolutionary Genetics), for example, told us about being "digitally-abled" and the "quill pen problem." Daniel Ferreras (West Virginia University, Foreign Languages) implored us to empower students to show us the way. "We are preceding history in the making."

Concurrent presentations included case studies from many universities at varying stages of ETD projects. These included Harvard, Humboldt University (Berlin), MIT, Michigan State University, University of Arizona, University of Georgia, University of Iowa, University of Waterloo, Virginia Commonwealth University, West Virginia University, as well as Virginia Tech. Australian and German national projects were also described. There were hands-on opportunities to learn about a variety of topics including HTML, PDF, SGML, XML, $\mathrm{XSL} / \mathrm{T}$, and metadata.

The conference was also an opportunity to network informally, especially during Friday evening's reception which was accompanied by music performed by West Virginia
University's John Hagen (ETDs/Library) and Daniel Ferreras (faculty/Foreign Languages). The Dali Museum was opened to us for an evening reception and self-guided tours. Lunches also afforded conference-goers the opportunity to enjoy the outdoors, especially the palm trees and the bay.

On the day before the conference, the Networked Digital Library of Theses and Dissertations (NDLTD) Steering Committee met to discuss accomplishments and to focus on future directions. Three subcommittees were established, with membership later drawn from volunteers among the conference attendees. In addition to planning next year's conference, the topics are training graduate students and standards and preservation. Each committee held initial meetings at the conclusion of Thursday's conference lunch, but new members are welcome. Progress reports will be prepared for the next Steering Committee meeting in Washington, D.C. on September 29, 2000.

NDLTD is a loose federation of 78 members from universities throughout the world, more than double the membership at this time last year when the conference was held in Blacksburg at Virginia Tech. At that time, two universities required that graduate students deposit ETDs. Four universities now require ETDs and there are more than 7,500 ETDs available from the member institutions. Next year the 4th International Symposium on Electronic Theses and Dissertations will be held at Cal Tech in Pasadena on March 22-24, 2001.

\section{Note}

1. See sites from the conference wrap-up session at http://scholar.lib.vt.edu/ presentations/ETDs2000/wrapup.pdf.

("For better ..." continued from page 407) search," a Special Issue of Astronomy and Astrophysics, Supplement Series, 143, no. 1 (April 2000), http://www.edpsciences-usa.org/ articles/astro/abs/2000/07/contents/contents. html NASA Astrophysics Data System.

5. The NASA Astrophysics Data System is located at http://adswww.harvard.edu.

6. Richard E. Luce, "The Open Archives Initiative: Forging a Path Toward Inter-operable Author Self-Archiving Systems," CERL News 61 (March 2000): 184-186, 202. 


\section{"Our Most POPUlar BUSINESS REFERENCE SOURCE... \\ Robin Gardella

Our directories get used, abused and mangled. Why? Because everybody needs our reference products for everyday life. For example:

\section{- JOB SEEKERS \\ - SALES PEOPLE \\ - ENTREPRENEURS \\ - STUDENTS}

\section{- CONSUMERS \\ - PROFESSORS \\ - NEWS MEDIA \\ - LAW LIBRARIES}

infoUSA Inc.'s products contain company name, address, phone number, SIC codes, estimated sales volume, number of employees, credit rating code*, key executive names, and more. Virtually all U.S. businesses - public and private.

Internet Access - Reference USA ${ }^{\oplus}$ Enjoy real-time access to the world's finest database of 10.5 million businesses and 100 million U.S. residents with comprehensive coverage, accuracy and instant access to information. And that's just the beginning! With its power, speed and user-friendly interface, Reference USA becomes the most effective, easy-to-use reference tool available. Customized reports, immediate downloads and business profiles are a snap!

American Business Disc ${ }^{\circledast}$ is the ultimate reference tool for Libraries. Imagine having over 10 million businesses on a single CD-ROM! Search by Company Name, Address, SIC Code(s), Yellow Page Heading, Sales Volume, Number of Employees, Geographically by ZIP Code(s), City(ies), State(s), or even the entire U.S.

American Manufacturers Directory \& CD-ROM contain every manufacturer in the U.S. with 20 or more employees, more than 168,000 total listings - all in two volumes. The CD-ROM contains all 645,000 manufacturers.

Big Businesses Directory \& CD-ROM include America's largest companies, 193,000 companies that employ 100 or more people. This directory also includes 703,000 top Executives and Directors.

State Business Directories are the most popular directories in every reference department. Before your patrons research any other source, point them to our publications. Four easy-to-use sections include: Businesses by City, Businesses by Yellow Page Category, Major Employers, and Manufacturers by City and Product.

State Credit Directories $\& \boldsymbol{C D}$ - $\mathrm{RO} \boldsymbol{M}$ are the most convenient Business Credit Reference Tools available! They make finding credit information fast, easy and affordable for all 50 states, plus Washington, D.C. And the business information included is invaluable for many applications.

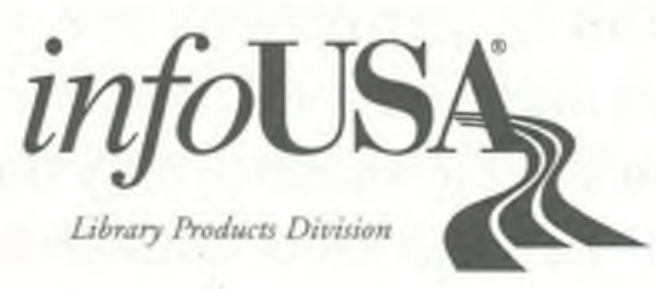

For More Information Call Toll-Free: (800) 808-1113 or E-mail: library@infoUSA.com
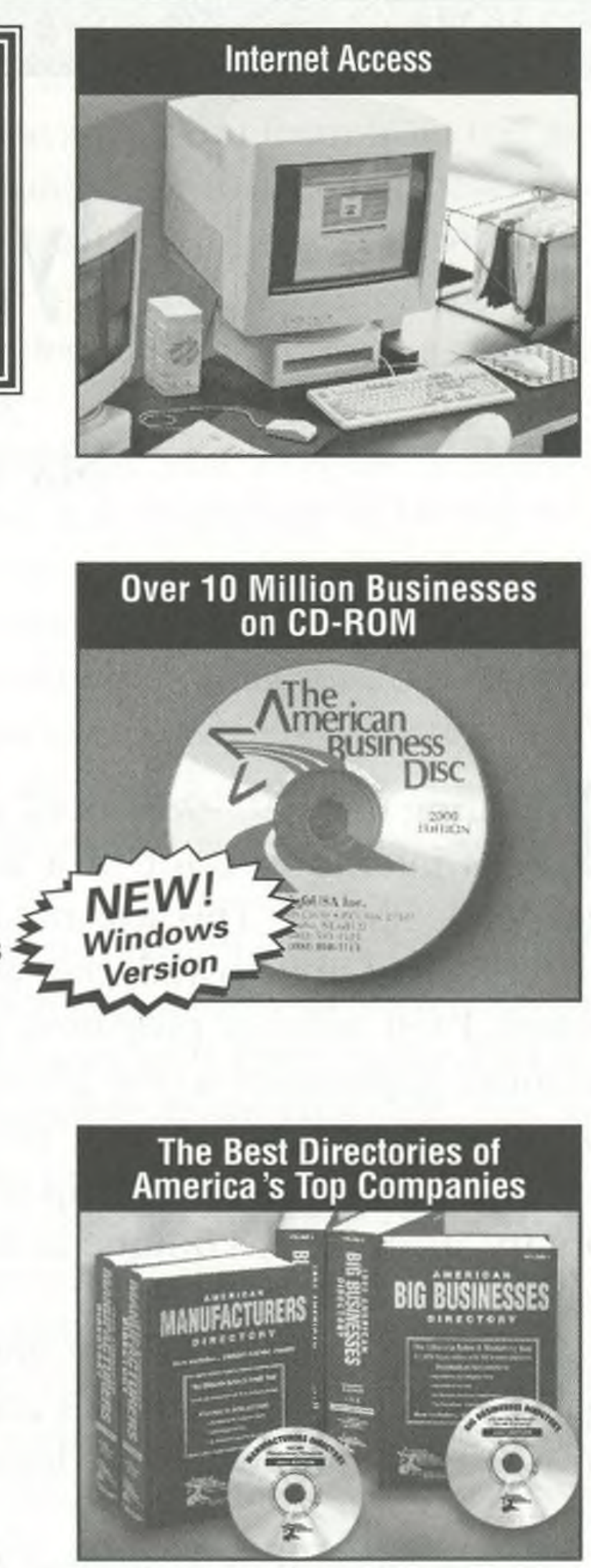

Available for All 50 States

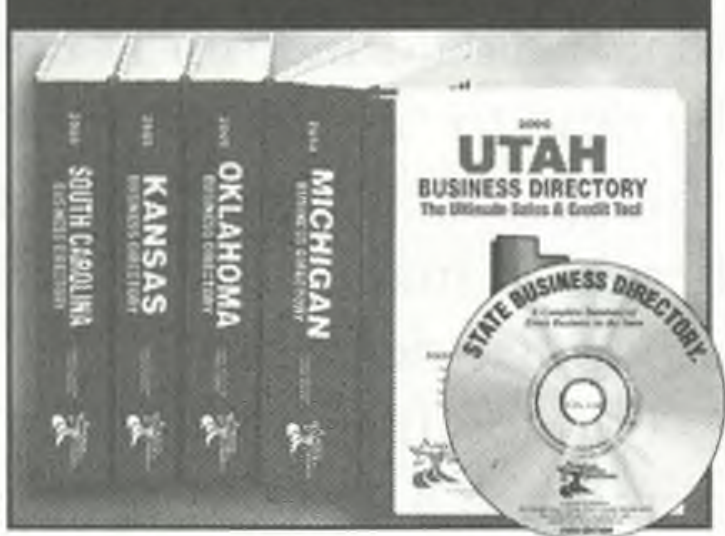

Business Credit Reference Tool!

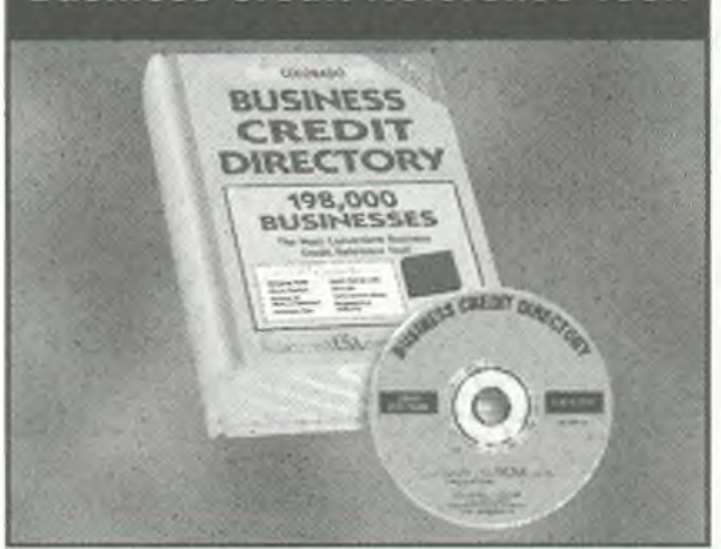

123710 